\title{
THE RELATIONSHIP OF ALEXITHYMIA TO THE HOUSE-DRAWING-TEST AND THE ROOM-DRAWING-TEST
}

\author{
Kotaro UMEMURA \\ Kyoto University, Japan
}

\begin{abstract}
This study aimed to examine the relationship of alexithymia to the House-DrawingTest and the Room-Drawing-Test, to identify what the Room-Drawing-Test can capture, and which drawing features should be focused when analyzing this test. In total, 433 undergraduate female students were classified into four subgroups based on cluster analysis using the subscale scores of the Japanese version of the 20-item Toronto Alexithymia Scale (TAS-20). Group characteristics were discussed/compared based on their drawings using self-developed analysis indicators. The most alexithymic group showed significant features regarding perspective and space composition in the Room-Drawing-Test; participants had a vague distinction between the internal and external worlds, and faced difficulties to have an integrated perspective toward and to relate to the internal world. The significance of the Room-Drawing-Test when elucidating individuals' attitudes toward the internal/ external worlds and that of focusing on perspective and on the degree of differentiation/elaboration of the interior space when analyzing this test, were highlighted.
\end{abstract}

Key words: Room-Drawing-Test, House-Drawing-Test, alexithymia

\section{INTRODUCTION}

In the House-Tree-Person (HTP) test - the most well-known projective drawing technique devised by Buck (1948) - the house is one of the objects requested to be drawn. The drawing of the house (hereinafter House-Drawing) is said to consciously and unconsciously reflect individuals' recognition, feelings, and attitudes toward home life/family relationships (Takahashi, 1974), and appears to be widely used in clinical settings owing to it being a useful/valuable instrument. Although the House-DrawingTest is a widely utilized technique, the Room-Drawing-Test is relatively unknown. The latter is a projective drawing technique invented by Tokuda (1981); it begins with the House-Drawing-Test, after which the drawer is asked to imagine and draw a room inside the house. The drawing of the room (hereinafter Room-Drawing) is assumed to reflect individuals' internal world. Therefore, the Room-Drawing-Test may give us a glimpse of individuals' distance/attitude toward their internal worlds, offering effective clues to individuals' psychological experiences and features.

Some studies have been conducted using the Room-Drawing-Test. According to Nishi (2018), they are largely divided into two kinds: some focused on the Room-

Correspondence concerning this article should be addressed Kotaro Umemura, Graduate School of Education, Kyoto University, Japan (e-mail: umemura.kotaro.5u@kyoto-u.ac.jp). 
Drawing-Test itself, while others attempted to grasp individuals' characteristics through it. An example of the former is Samizo (2006), who examined the meaning of the boundary line drawn in the Room-Drawing-Test in relation to the YG Personality Inventory. By conducting comparisons regarding psychological traits — as assessed by the YG Personality Inventory - between subjects who drew boundary lines in the RoomDrawing-Test and those who did not, the author suggested that the drawing of the boundary line is influenced by personality traits related to the internal world. As an example of the latter, Yamamori (2002) demonstrated the characteristics of the RoomDrawings of patients with Graves' disease; compared with the control group, people with this disease showed hindrances regarding perspective drawing; tended to draw the floormap of the room from a top-down perspective; and some drawings were done from multiple viewpoints. Thus, from the findings of these previous studies, when analyzing the Room-Drawing-Test, it seems reasonable to give greater importance to structural analysis (i.e., how the picture is drawn, like its spatial composition, boundary line, and perspective) compared with content analysis.

Although this test has shown great potential for understanding individuals' attitudes toward their internal worlds, it has only been used in a few studies - carried out in Japan - so it needs refinement; this implies the need to accumulate literature on the topic. Especially, it seems important to emphasize which personality traits it can approach/ clarify, and which aspects of the Room-Drawings should be focused on when they are being analyzed. When considering the most appropriate study direction in the present circumstances, and when viewing previous studies that used the Room-Drawing-Test afresh, it may be found that in many cases psychosomatic illnesses, broadly rather than strictly defined, were the subject of the research; i.e., pathological conditions in which psychological factors impact physical health, such as anorexia nervosa (Tokuda, 1981), Graves' disease (Yamamori, 2002), hyperventilation syndrome (Furuno, 2005), and psychosomatic diseases in general (Umemura, 2015, 2016). These studies have demonstrated the general features of such patients by comparing/analyzing their RoomDrawings against those of control groups; therefore, it may be an effective technique to capture the psychological characteristics of psychosomatic patients.

Accordingly, I focused on the concept of "alexithymia," a usual feature of psychosomatic patients; this term, coined by Sifneos (1973), denotes a difficulty in verbalizing/recognizing one's feelings that have been observed during clinical practice. Another conceptualization states that alexithymia is a multifaceted personality construct characterized by: (1) difficulty to identify one's own feelings and to distinguish them from bodily sensations related to emotional arousal; (2) difficulty to describe feelings to other people; (3) constricted imaginal processes, as evidenced by a scarcity of fantasies; and (4) a stimulus-bound externally-oriented cognitive style (Taylor et al., 1997). This concept has recently been discovered to be associated with various health and behavioral problems, not only psychosomatic disease; e.g., depression ( $\mathrm{Li}$ et al., 2015), eating disorders (Westwood et al., 2017), alcohol use disorders (Thorberg et al., 2009), and excessive internet use (Kandri et al., 2014). It has also been integrated into the broader field of emotion research and is attracting a lot of attention as a significant psychological 
feature (Taylor \& Bagby, 2004; Taylor et al., 1997). Given that psychotherapy requires patients to explore their inner worlds by performing voluntary narratives/self-reflective attitudes, persons with alexithymia are often not affected by psychotherapy as many others would; thus, alexithymia is an important concept to be considered when judging the applicability of psychotherapy. In summary, it seems important/valuable to understand how the Room-Drawing-Test relates to this psychological trait in order to contribute to the literature on it.

Moreover, although I focused on the Room-Drawing-Test, I also examined the relationship between alexithymia and the House-Drawing-Test, which is conducted immediately before the Room-Drawing-Test. Although the House-Drawing-Test has been historically perceived as a useful representation of individuals' recognition, feelings, and attitudes toward home life/family relationships, in this study, I assumed that it reflected one's relationship with the surrounding external world. This type of interpretation finds consonance in the literature (e.g., Tokuda, 1981; Inoue, 1984). Considering that alexithymia refers to not only the internal but also the external world-it comprises a stimulus-bound externally-oriented cognitive style - people may express their alexithymiarelated characteristics through House-Drawings because these highlight drawers' attitudes toward the external world. Thus, the House-Drawing-Test may serve as a useful reference point to ensure an accurate understanding of the Room-Drawing-Test.

This study aimed to examine the relationship of alexithymia to the House-DrawingTest and the Room-Drawing-Test, to identify what the Room-Drawing-Test can capture, and to identify which drawing features should be focused on when analyzing this test.

\section{Method}

\section{Participants}

Study participants were undergraduate students, predominantly freshmen, in a private women's university in Japan. There were initially 438 participants but 5 were excluded after they failed to complete the questionnaire. I accordingly analyzed data from 433 participants (average age: $19.30 ; S D=0.58$; age range: $18-23$ years old).

\section{Materials}

Japanese version of the 20-item Toronto Alexithymia Scale (TAS-20; Bagby, Parker, \& Taylor, 1994; Bagby, Taylor, \& Parker, 1994; Komaki et al., 2003). This is a self-assessed 20-item questionnaire used to measure alexithymia tendency. It is regarded as the most reliable/valid scale for this construct and its translated versions are widely used internationally (Bagby et al., 2020). It has three subscales: Difficulty in Identifying Feelings (DIF; 7 items); Difficulty in Describing Feelings (DDF; 5 items); and Externally Oriented Thinking (EOT; 8 items). Items are rated a 5-item Likert-type scale ranging from 1 (not at all applicable) to 5 (very applicable).

House-Drawing-Test. Participants were instructed to place an A4-sized Kent paper horizontally, use 2B pencils, an eraser, and orally instructed as follows: "Please, imagine a house, you can imagine any type of house you would like. Please, draw the outside of the house." After finishing the drawing, they were asked to write down, on the entry column of the questionnaire, what they were imagining about the house while drawing.

Room-Drawing-Test. The initial procedure was similar to that of the House-Drawing-Test, but the oral instruction changed as follows: "Please, look at the house you drew and imagine a room inside it. Then, 
imagine you are in the room and are looking around. Please, draw what you see." After finishing the drawing, they were asked to write down, on the entry columns of the questionnaire, what they drew and what they were imagining about the room while drawing.

\section{Procedures}

This research was conducted during undergraduate classes in November and December of 2014 and 2015. I provided the students with a masked explanation on study aims (i.e., to investigate the relationship between one's physical health and characteristics) as well as the ethical considerations described herein: (1) participation was optional; (2) non-participation would not result in any detrimental affect; (3) data would be used solely for research purposes; (4) data confidentiality was ensured; (5) data management methods were described; and (6) locus of responsibility. Only the students who understood these considerations and agreed to cooperate with this research were asked to provide their consent and state their ages in the questionnaire. After informed consent was acquired, study procedures occurred in the following order: (1) application of the questionnaire about individual history of psychosomatic diseases; (2) the TAS-20; (3) the Baum Test; (4) the House-Drawing-Test, and (5) the Room-Drawing-Test. Since this paper does not address the results of (1) and (3), they were omitted. After conclusion of study procedures, I explained research aims in greater detail and gave a lecture about psychosomatic diseases and alexithymia.

\section{Data Analysis}

Although the TAS-20 is the most reliable/valid scale to measure alexithymia trait, it also has limits; there may be a risk of false-positives (e.g., neurotic/depressive participants may rate higher than their true rates) and false-negatives (e.g., participants with severe alexithymia may have difficulties to accurately assess their own abilities, so they might rate lower than their true rates; Sriram et al., 1988; Taylor et al., 1997). In fact, Ueno et al. (2014) found that those who showed high TAS-20 total scores included two groups with different distinctive features: while one group showed high scores for DIF and neuroticism, the other had high scores for EOT and low scores for openness to experience; then, the authors considered that participants in the first group were not alexithymic, while those in the latter were. Moreover, in teenagers, the DIF and DDF scores tend to be higher compared with other age groups (Moriguchi et al., 2007); thence, in a group of teenage participants with high TAS-20 total scores, there may be many that are not alexithymic. In summary, as the TAS-20 total score alone does not serve as an accurate assessment of alexithymia trait, I was careful when analyzing participants' TAS-20 total scores.

To assess participants' alexithymia traits correctly, by referencing Ueno et al. (2014), I classified them by the subscales of the TAS-20. I conducted a hierarchical cluster analysis by Ward's method using the score of the TAS-20 subscales as clustering variables. Considering the obtained dendrogram and the interpretability of the clusters, I chose a four-cluster/four-subgroup solution. One-way analyses of variance were used to determine between-subgroup significant differences regarding the TAS-20 total score, and the scores in the DIF, DDF, and EOT subscales.

Moreover, drawing evaluations were conducted. Since an analysis method had not been established, especially for the Room-Drawing-Test, I first looked through the participants' drawings and created a preliminary and comprehensive set of analysis indicators that aimed to capture their features. The finally adopted analysis items were selected from the set that met one of the following criteria: (1) those that had been recognized as important in previous studies; (2) those that appeared frequently; and (3) those that were assumed to be theoretically/symbolically important. The author, another clinical psychologist, and an undergraduate clinical psychology student separately evaluated all drawings based on the analysis items; evaluators were asked to assess the items by choosing whether they were applicable or not. A final rating for an item was determined when the evaluation was agreed by at least two thirds of the evaluators. To examine item frequency differences for both drawings by subgroup, I used Fisher's exact test, and residual analyses were conducted for items that showed statistically significant differences. 


\section{RESULTS}

\section{Examination of the Measurement Scale}

Table 1 shows the means, SDs, Cronbach's alpha coefficients, and mean inter-item coefficients (MICs) of the TAS-20. The DIF demonstrated high internal consistency, and the TAS-20 total score and the DDF had adequate reliability. Since a range of .20 to .40 for MICs is considered optimal, and that of .10 to .50 is also considered acceptable for multifactorial scales (Briggs \& Cheek, 1986), the MICs of the TAS-20 total score, the DIF and the DDF were within this range, I deemed them to be homogeneous. Meanwhile, the alpha coefficient and the MIC of the EOT were less than adequate; nonetheless, this result finds consonance in the literature, especially in studies conducted in non-English-speaking countries that used the translated version of this scale (Taylor et al., 2003). For example, Komaki et al. (2003) reported that the alpha coefficients of the Japanese version of the TAS-20 had similar low alpha coefficients for the EOT subscale.

Factor validity was examined by confirmatory factor analysis. The model concordance indicators were as follows: comparative fit index $(\mathrm{CFI})=.870$; root-meansquare error of approximation (RMSEA) $=.053$; adjusted goodness of fit index (AGFI) $=.879$; standardized root-mean-square residual $(\mathrm{SRMR})=.054$. These values denote generally acceptable fits. Concluding, although the EOT subscale may not have presented sufficient consistency, the other results were comprehensive enough, thus, in the data analysis, I decided to use all scales in their original form.

\section{Participants' Classification}

Results showed that significant score differences were found in all dependent variables (TAS-20 total score: $F(3,429)=349.65, p<.001$; DIF: $F(3,429)=339.52, p$ $<.001$; DDF: $F(3,429)=170.44, p<.001$; EOT: $F(3,429)=61.45, p<.001)$. Therefore, I conducted multiple comparison by Tukey method. Table 2 shows the means and SDs of each scale by subgroup. To facilitate the process of grasping the characteristics of each cluster, Fig. 1 shows bar graphs that indicate the average of the standardized scores for each subgroup.

The first cluster $(N=108)$ showed the highest TAS-20 total score, DIF, and DDF scores, and a moderate EOT score. Namely, participants in this cluster tended to feel emotionally confused and to have difficulties when communicating their feelings to

Table 1. Means, SDs, Alpha Coefficients, and MICs of the TAS-20

\begin{tabular}{|c|c|c|c|c|}
\hline Scale & $M$ & $S D$ & $\alpha$ & MIC \\
\hline TAS-20 total score & 52.81 & 9.37 & .76 & .12 \\
\hline DIF & 17.13 & 5.73 & .81 & .38 \\
\hline DDF & 16.20 & 3.66 & .63 & .24 \\
\hline EOT & 19.48 & 3.65 & .50 & .11 \\
\hline
\end{tabular}


Table 2. Scale Scores of Subgroups and Test Results

\begin{tabular}{|c|c|c|c|c|c|c|c|}
\hline Scale & & $\begin{array}{c}\text { CL1 } \\
(N=108)\end{array}$ & $\begin{array}{c}\text { CL2 } \\
(N=73)\end{array}$ & $\begin{array}{c}\text { CL3 } \\
(N=142)\end{array}$ & $\begin{array}{c}\text { CL4 } \\
(N=110)\end{array}$ & $F$-value & Multiple comparison \\
\hline \multirow{2}{*}{$\begin{array}{l}\text { TAS-20 } \\
\text { total score }\end{array}$} & M & 64.09 & 49.34 & 54.14 & 42.32 & \multirow[t]{2}{*}{$349.65 * * *$} & \multirow[t]{2}{*}{$\mathrm{CL} 1>\mathrm{CL} 3>\mathrm{CL} 2>\mathrm{CL} 4$} \\
\hline & $S D$ & 5.85 & 5.30 & 3.99 & 5.25 & & \\
\hline \multirow[t]{2}{*}{ DIF } & $M$ & 24.61 & 17.00 & 16.06 & 11.25 & \multirow[t]{2}{*}{$339.52 * * *$} & \multirow[t]{2}{*}{$\mathrm{CL} 1>\mathrm{CL} 2 \cdot \mathrm{CL} 3>\mathrm{CL} 4$} \\
\hline & $S D$ & 3.62 & 2.27 & 3.50 & 2.50 & & \\
\hline \multirow[t]{2}{*}{ DDF } & $M$ & 19.80 & 16.53 & 16.38 & 12.22 & \multirow[t]{2}{*}{$170.44 * * *$} & \multirow[t]{2}{*}{$\mathrm{CL} 1>\mathrm{CL} 2 \cdot \mathrm{CL} 3>\mathrm{CL} 4$} \\
\hline & $S D$ & 2.54 & 2.85 & 2.36 & 2.26 & & \\
\hline \multirow{2}{*}{ EOT } & $M$ & 19.69 & 15.81 & 21.70 & 18.85 & \multirow{2}{*}{$161.45 * * *$} & \multirow{2}{*}{$\mathrm{CL} 3>\mathrm{CL} 1 \cdot \mathrm{CL} 4>\mathrm{CL} 2$} \\
\hline & $S D$ & 3.77 & 2.39 & 2.84 & 2.93 & & \\
\hline
\end{tabular}

$* * * p<.001$.

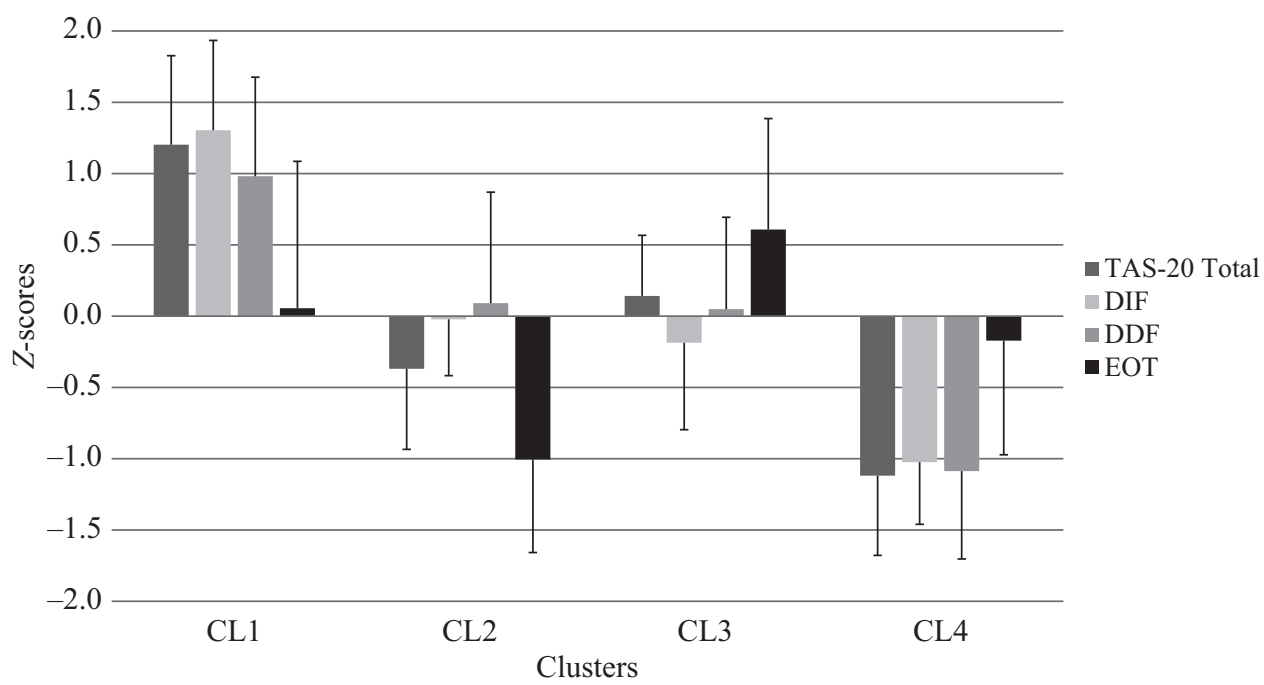

Fig. 1. Participants' Standardized Scores of the TAS-20 by Subgroup

others, but they were not alexithymic in that they were not totally uninterested in their internal worlds. This suggests that they had neurotic tendencies; such predisposition inflated their DIF and DDF scores and caused the false increase in the TAS-20 total score. Hence, this group was named the "Neurotic" group.

The second cluster $(N=73)$ showed the lowest EOT and moderate DIF and DDF scores. Participants in this group had high interest in their internal worlds, so it was named the "Internally Oriented" group.

The third cluster $(N=142)$ showed the highest EOT and moderate DIF and DDF 
scores. In a previous study (Arimura et al., 2002), the EOT was the only subscale that showed a significant positive correlation with the Structured Interview by the modified edition of the Beth Israel Hospital Psychosomatic Questionnaire (SIBIQ), which objectively assesses alexithymia through interview by trained clinicians; this denotes that this subscale should be emphasized when evaluating alexithymia. Thus, although this cluster had the second highest TAS-20 total score, participants in it were deemed as the most alexithymic of my sample. Hence, it was named the "Alexithymic" group.

The fourth cluster $(N=110)$ showed the lowest TAS-20 total score, DIF, and DDF scores, and moderate EOT scores. Participants in this group seemed to be confident in identifying and communicating their own feelings, so it was named the "Emotionally Stable" group.

\section{Analysis of Drawings}

Tables 3 and 4 show the results of the drawing items analyses.

\section{Discussion}

\section{Characteristics of Each Group's Drawings}

In this section, based on the analysis results of House-Drawing-Test and RoomDrawing-Test, I discuss the features of each group, referring to the analysis items that showed significant differences and those that showed marginally significant differences.

Neurotic group. In the House-Drawing-Test, this group showed more drawings with [no door] than the other groups. Since the door denotes direct/active interaction with others, its absence may signify a lack of emotional communication with others/family members, unwillingness to be approached by/to approach others, and a lack of warm feelings (Takahashi, 2011). Therefore, this characteristic in the Neurotic group suggests their psychological closedness, namely, their defensive attitudes toward the external world/others.

In the Room-Drawing-Test, this group showed more drawings with a [first-person view] (i.e., as if the drawer was actually in the room; Fig. 2) and fewer drawings with a [mix of perspectives] than the other groups. Thus, they seem to be trying to bundle all the possible views together under a single view by negating all others, and seem to be very self-conscious; this suggests that they are very self-reflective and bound to their selfconsciousness. Such excessive subjectivity may produce doubts toward their own ability to handle their feelings, thereby resulting in the observed inflated DIF and DDF scores.

Moreover, this group showed fewer drawings with [no boundary line] than the other groups. Tokuda (1981) associated a drawing with no boundary line with ambiguity about oneself. Yamamori (1999) also remarked that a drawing with no boundary line suggests a lack of differentiation between the internal and external state/worlds because it denotes that such boundary does not matter for that person. Given their considerations on the meaning of drawings where boundary lines were absent, my results suggested that those in the Neurotic group strictly distinguished their internal and external spaces and also had 


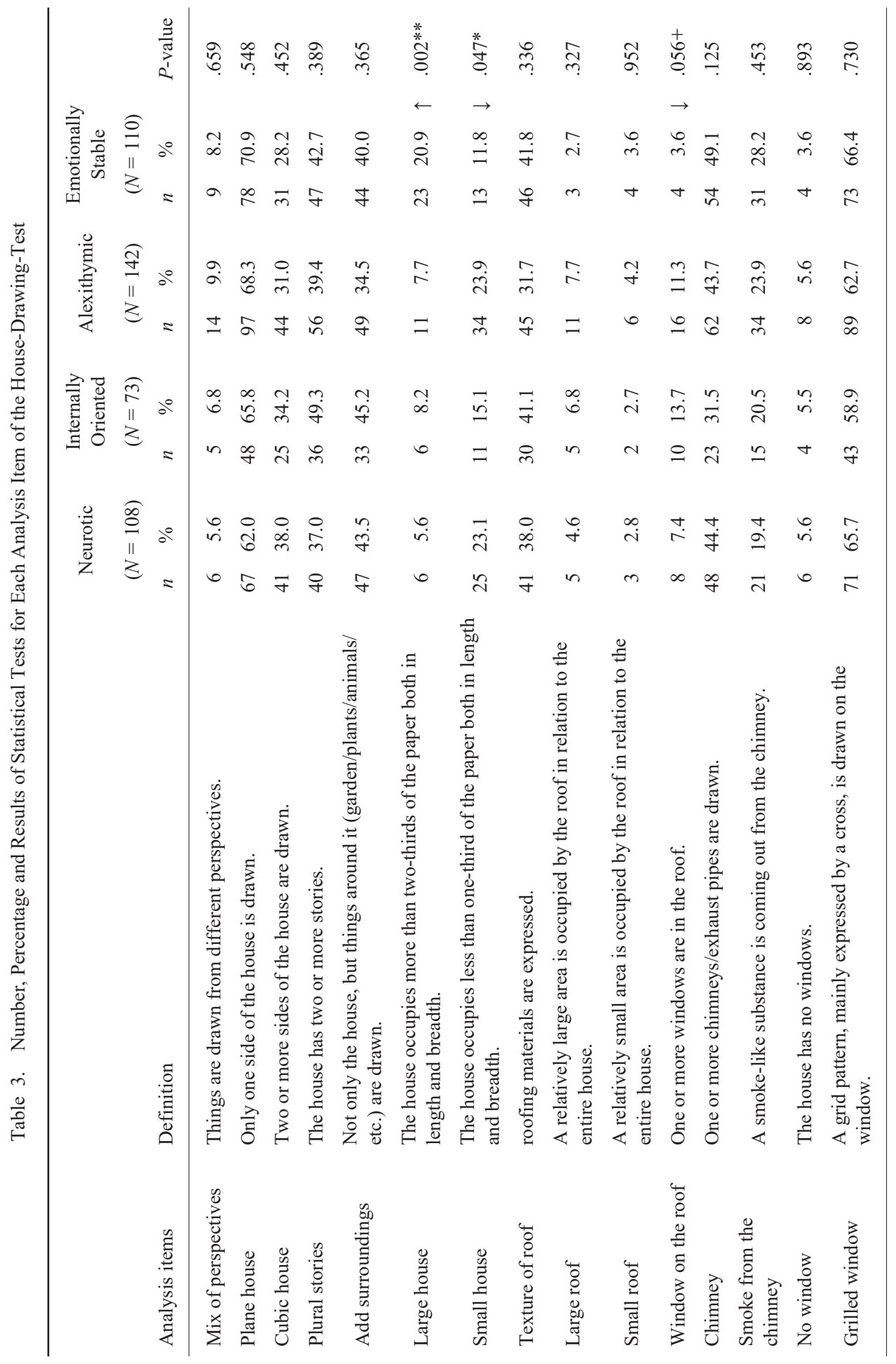




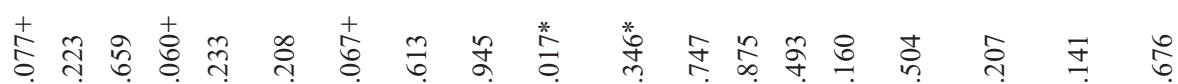

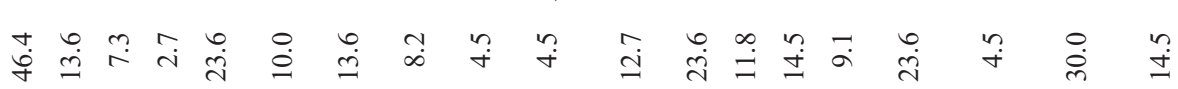

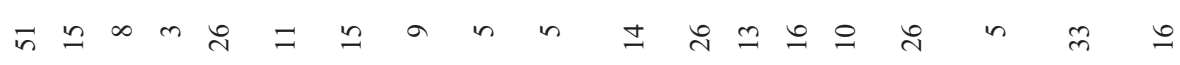

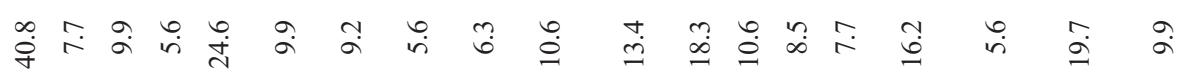

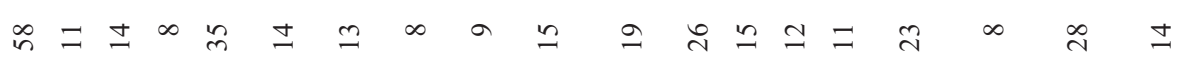

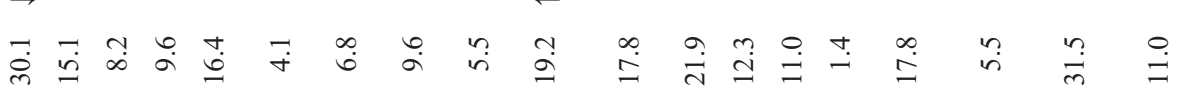

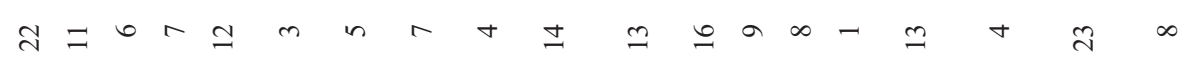

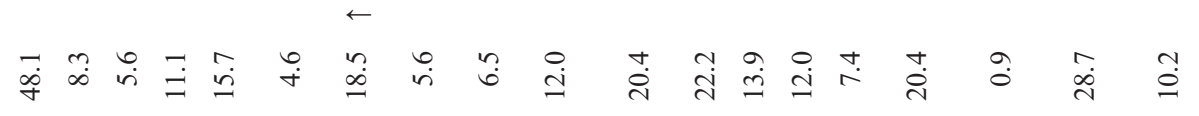

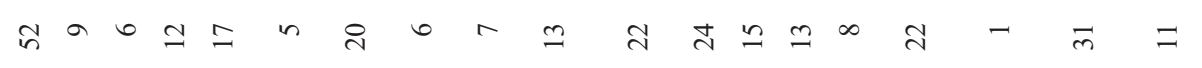

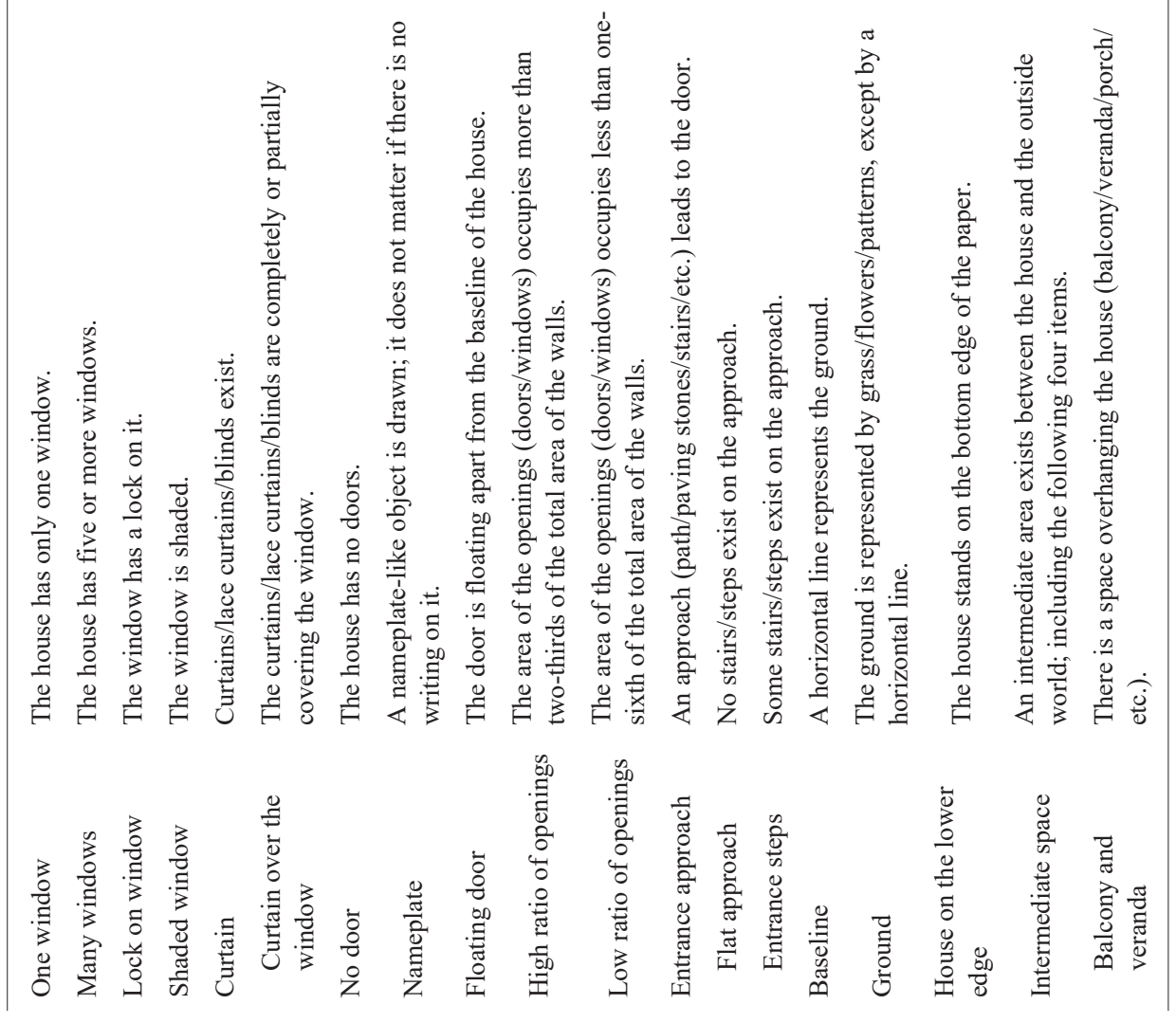




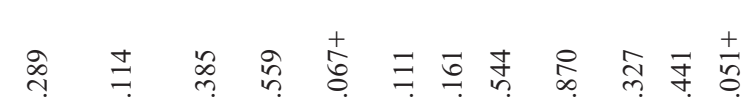

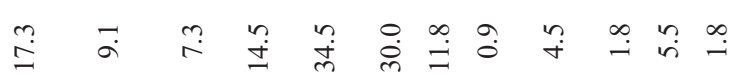

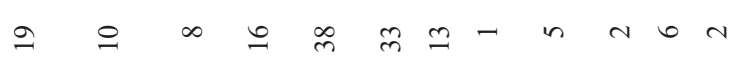

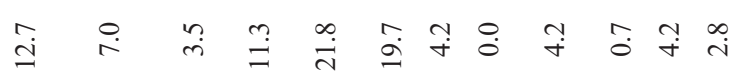

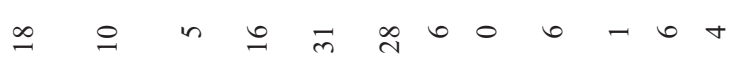

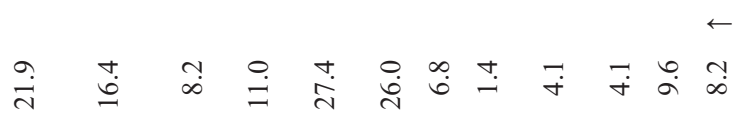

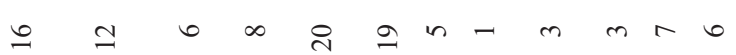

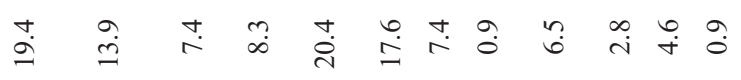

$$
\begin{aligned}
& \vec{\sim} \sim \infty a \text { ป } 2 \infty-\pi n-
\end{aligned}
$$

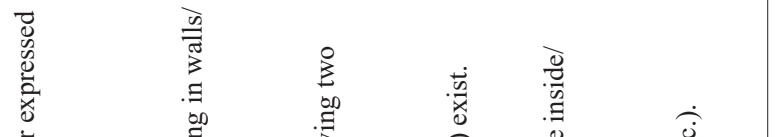

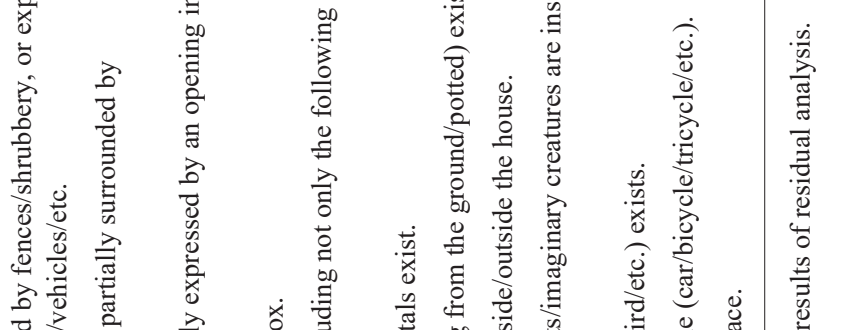

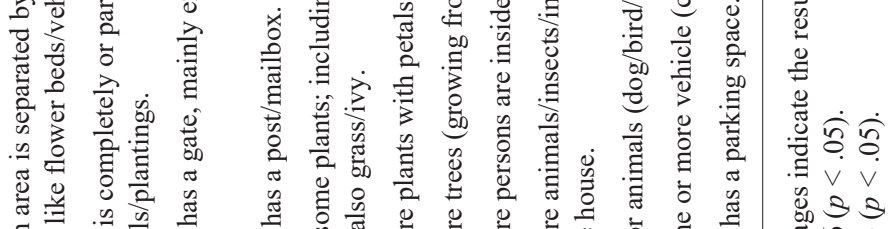

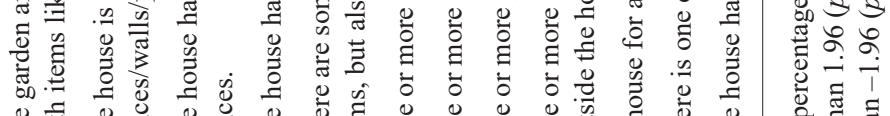

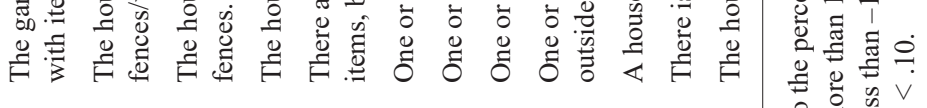

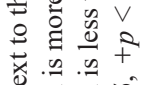

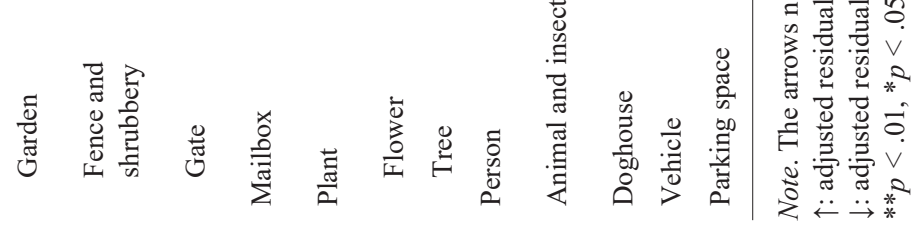




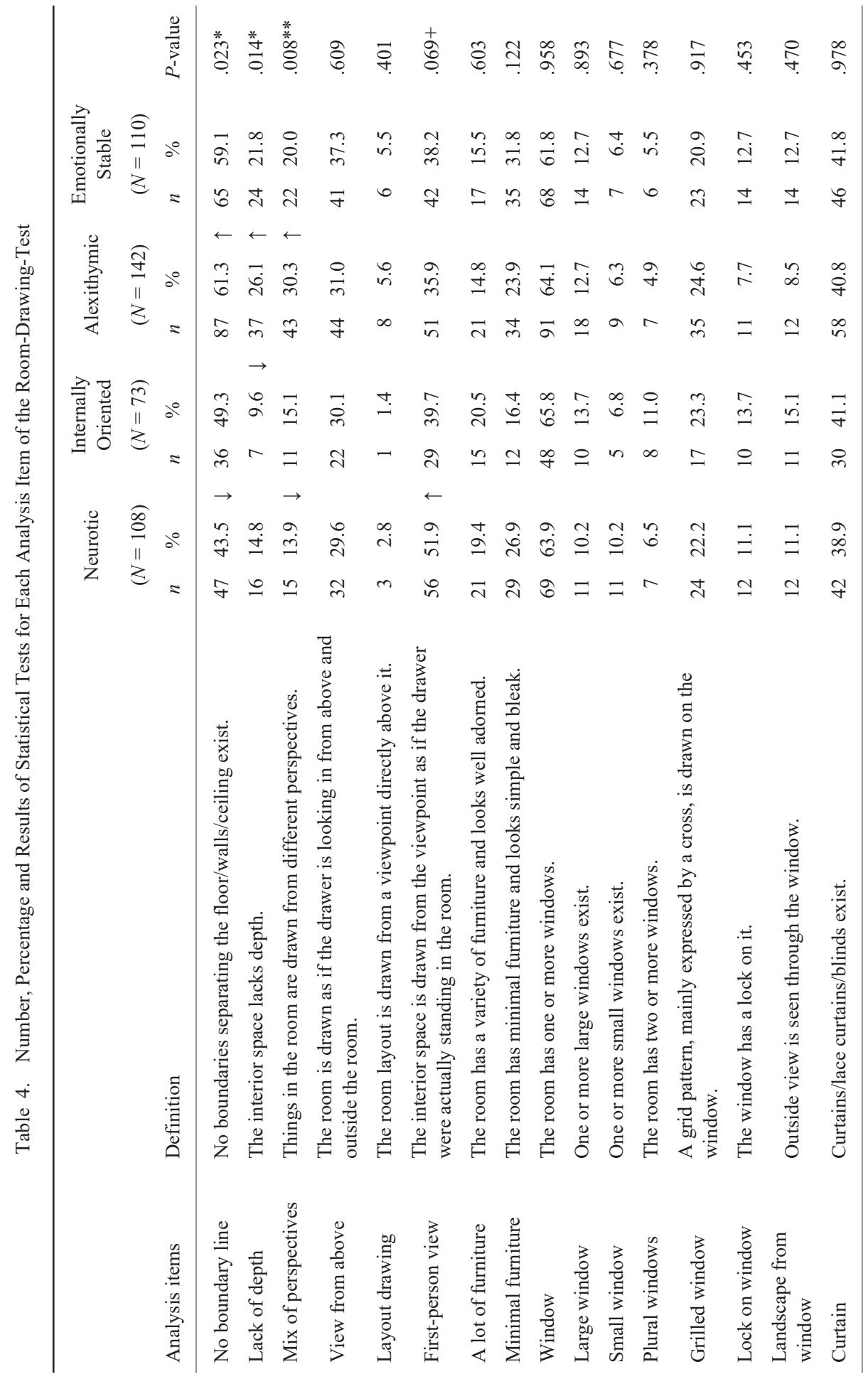




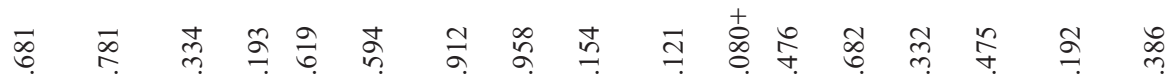

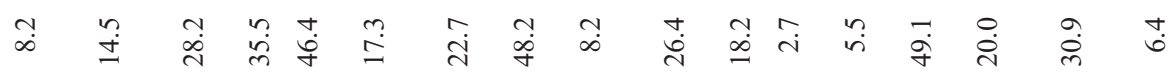
a 0 ल

n

ป $\vec{\pi}$ q

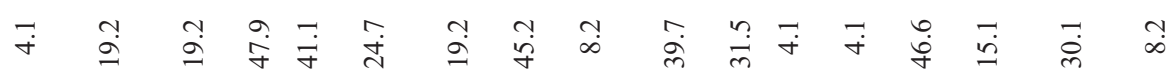

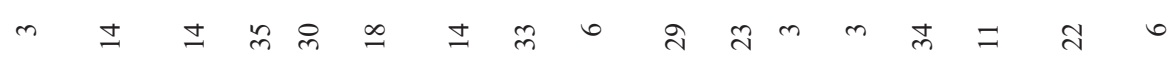

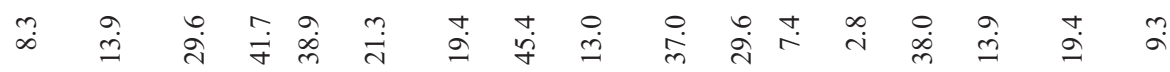

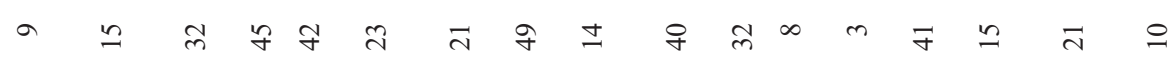

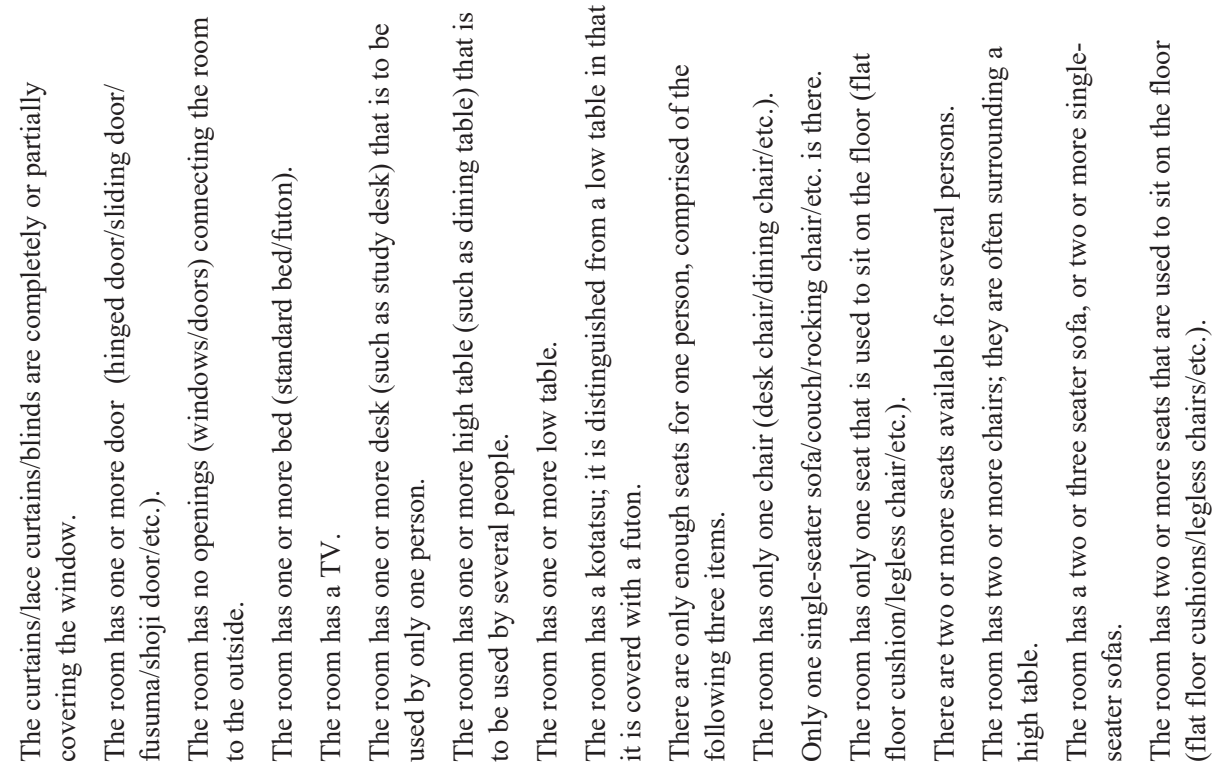

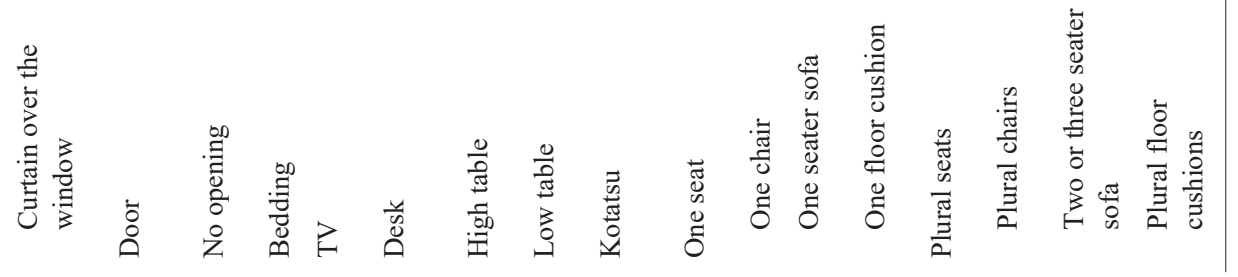




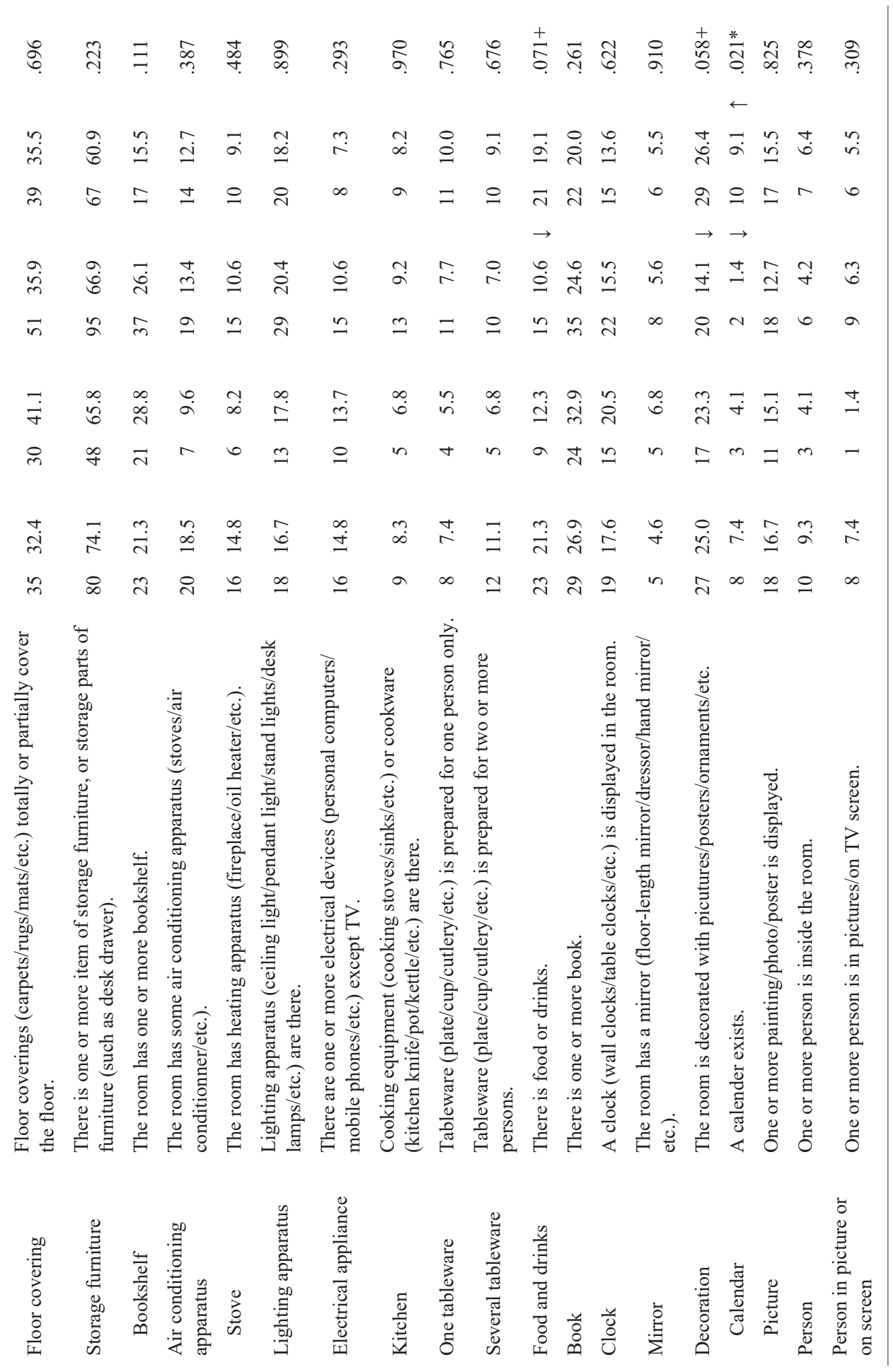




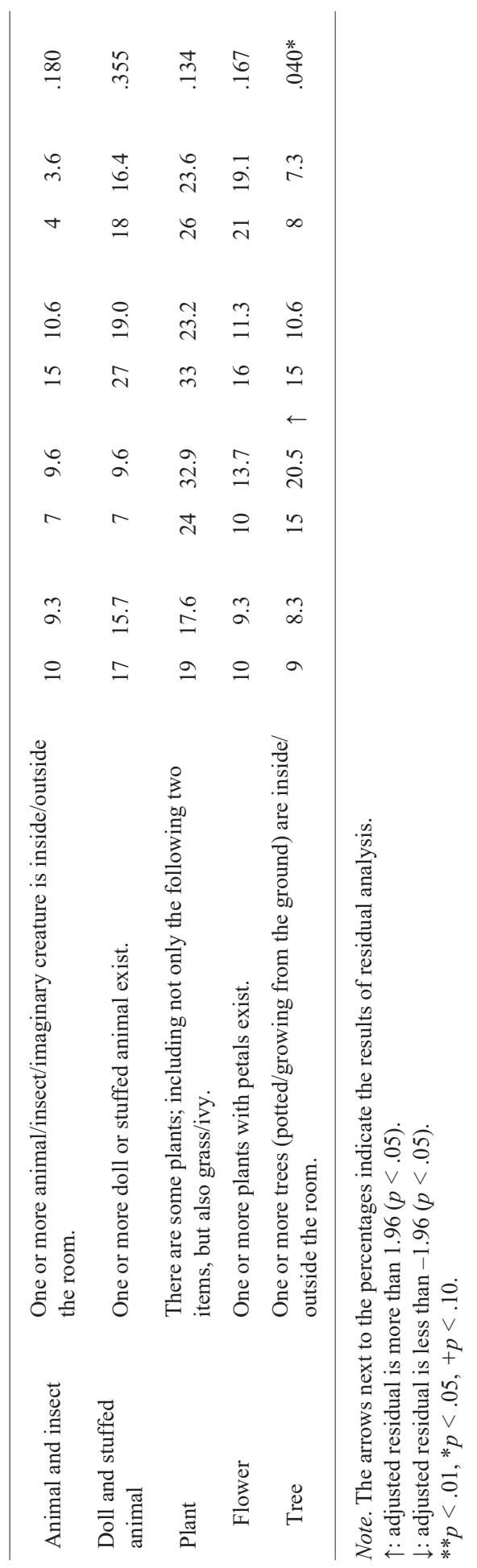




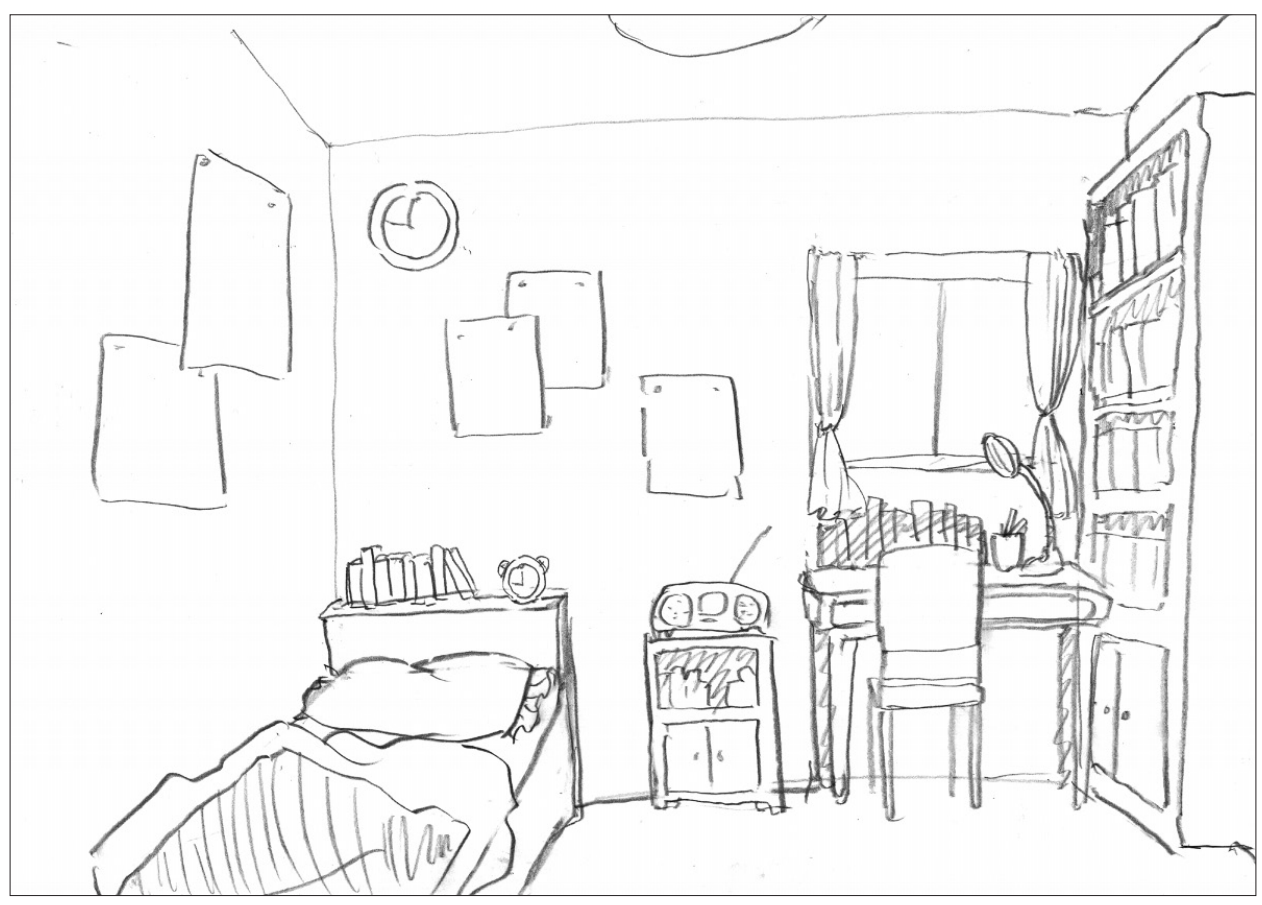

Fig. 2. Example of [First-Person View] in the Room-Drawing-Test by a Participant in the Neurotic Group

psychologically well differentiated internal worlds.

Internally Oriented group. In the House-Drawing-Test, this group showed fewer drawings with [one window] than the other groups, so they were more likely to draw more than one window; consequently, they showed more drawings with a [high ratio of openings] (Fig. 3). Additionally, this group showed relatively more drawings with a [parking space] compared with the other groups; nonetheless, the frequency is not very high. Considering that a [high ratio of openings] indicates active interactions with the external world and that the car is a means to contact the outside world, my results seemed incongruous with group characteristics; they are highly concerned with their internal worlds. However, Leibowitz (1999) interpreted drawings with many windows as a sign of effort to overcompensate for anxiety about their relationship with the outside world. Given that most of the participants were freshmen - who might still be in the process of adjusting to their new environments/relationships at the university - these features may indeed be signs of compensation for their introversion. However, these are only speculations and require further clarification about the true meaning of such indicators.

In the Room-Drawing-Test, this group showed fewer drawings with a [lack of depth] than the other groups. To imprint depth to a drawn room, it is necessary to construct the room space (i.e., to consider the relationship between interior items and position them in an integrated way from a fixed viewpoint); assuming that the inside of the room refers to one's internal world, a drawing with depth denotes one's commitment, sensitivity, and interest toward it. Because the Alexithymic group showed relatively 


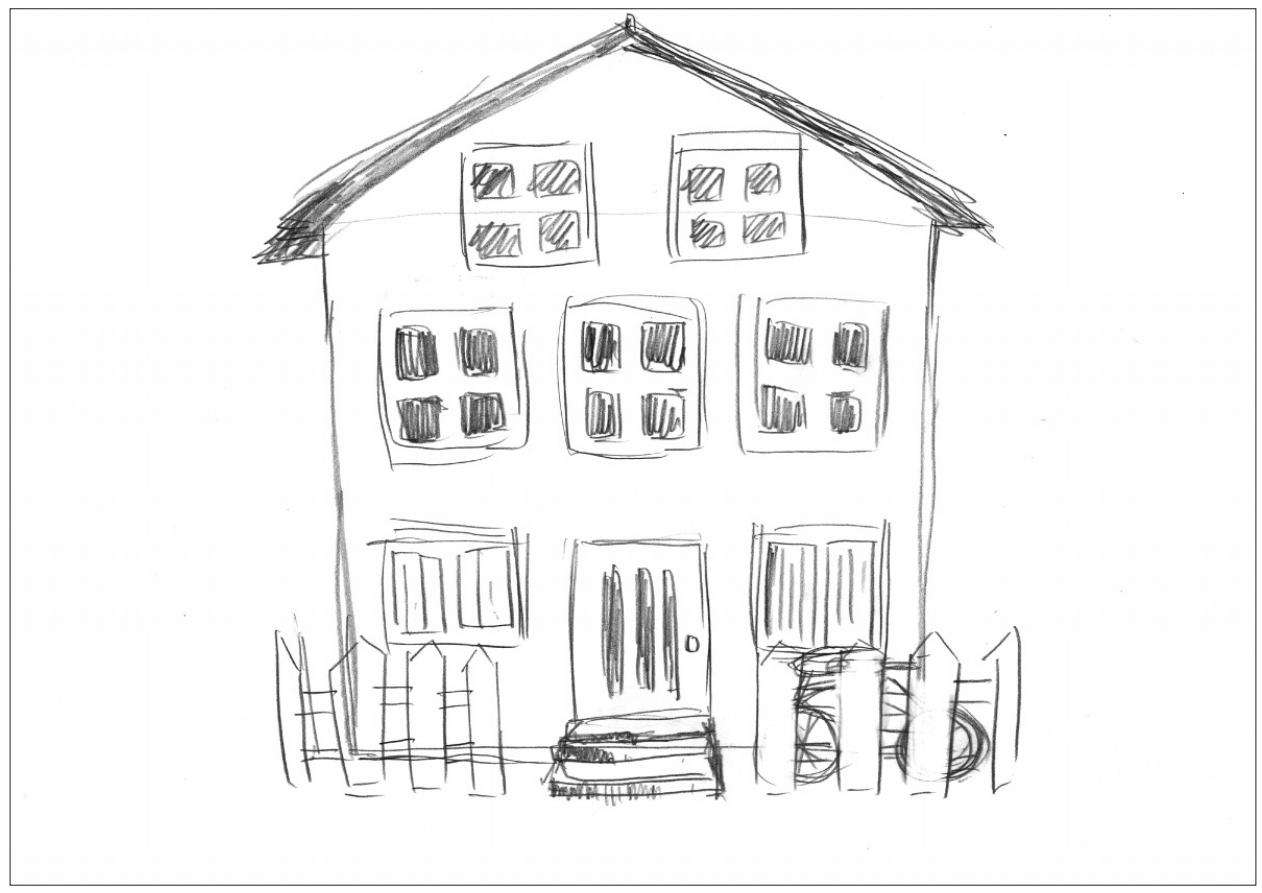

Fig. 3. Example of [High Ratio of Openings] in the House-Drawing-Test by a Participant in the Internally Oriented Group

more drawings with a [lack of depth], I have finalized this discussion under the "Alexithymic group" subheading.

The Internally Oriented group also showed more drawings with one or more [tree] than the other groups. The implications of this indicator are not clear because there is no literature on the meaning of trees in the Room-Drawing-Test; nonetheless, I speculate that this characteristic denotes the individual's interest towards their internal world, or the richness of their inner life, since it was observed more frequently in this group comprising more introverted participants.

Alexithymic group. In the House-Drawing-Test, this group did not show any significant differences regarding the frequency of drawing features compared with the other groups. Conversely, in the Room-Drawing-Test, this group showed more drawings with [no boundary line], a [lack of depth], and a [mix of perspectives] - all of which are related to perspective and space composition - than the other groups (Fig. 4, 5, and 6). These features have been found to relate to psychosomatic illnesses, as broadly rather than strictly defined, in the literature (Tokuda, 1981; Yamamori, 2002; Furuno, 2005; Umemura, 2015, 2016). Since these characteristics were prevalent in the Alexithymic group, my results suggest that they are highly related to the alexithymia trait.

While drawings with boundary lines denote a differentiation between inside and outside worlds, drawings with [no boundary line] denote a lack of concern for the presence/absence of division between these worlds. This may also explain why there 


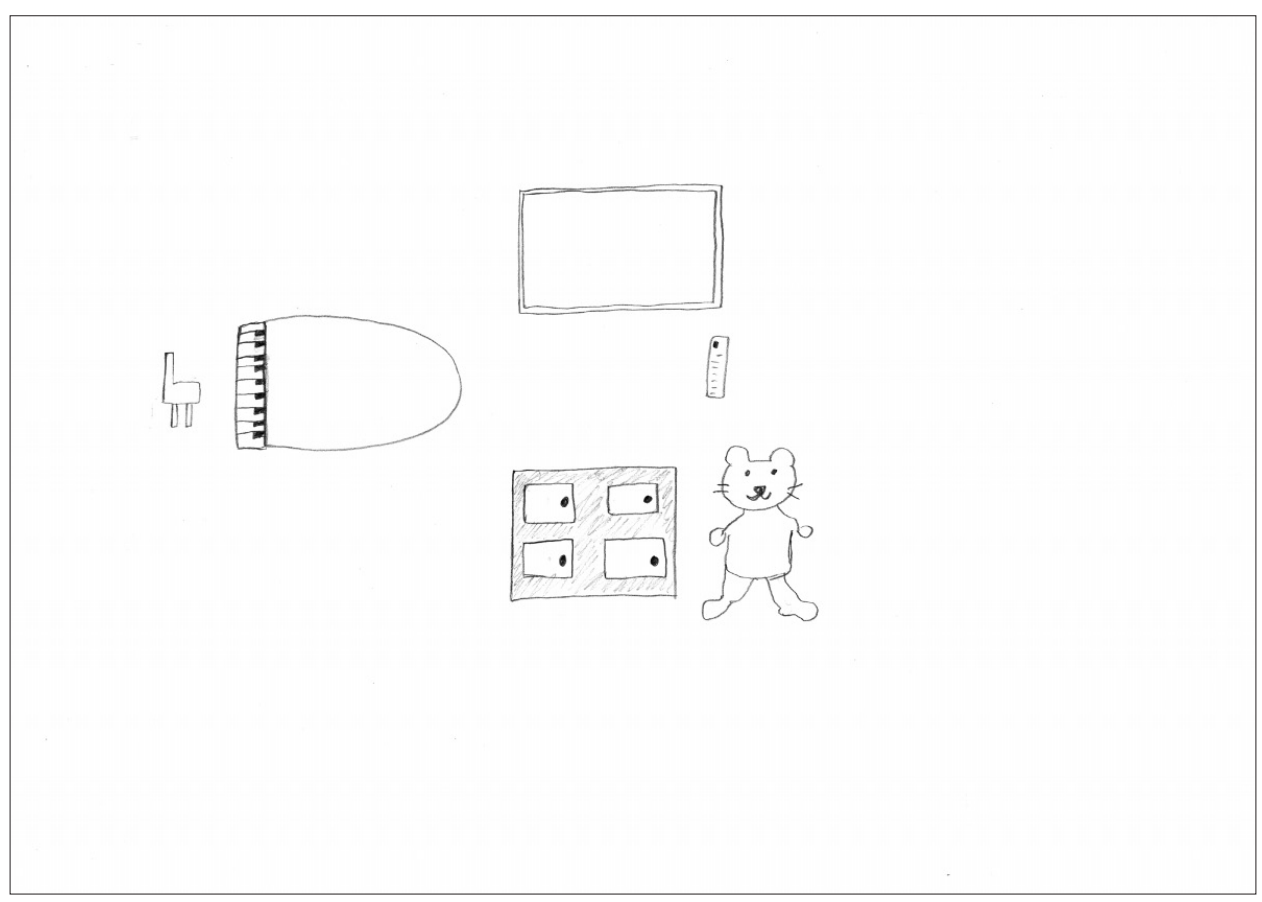

Fig. 4. Example of [No Boundary Line], [Lack of Depth], and [Mix of Perspectives] in the RoomDrawing-Test by a Participant in the Alexithymic Group

were fewer drawings with a [calendar] and a [decoration] (i.e., because these are usually hung on the walls/boundaries) in this group. Additionally, this group showed fewer drawings with [food and drinks], which serve to indicate the life activities of the house dwellers. Such lack of wall decorations and liveliness may be associated with the diminished interest toward the internal world found in participants of this group.

Emotionally Stable group. In the House-Drawing-Test, this group showed fewer drawings of a [small house] and more drawings of a [large house] than the other groups (Fig. 7). In this group, these characteristics may denote high psychological energy, activeness, or even self-esteem. This group also showed fewer drawings with a [high ratio of openings]; this may owe to a higher frequency of drawings of a [large house] because the opening area tends to be proportionally smaller when the wall area is large. Moreover, this group showed more drawings with one or more [plant] around the house than the other groups (Fig. 7); since drawing the environment around the house in the House-Drawing-Test means that participants expanded the initial instruction (i.e., "draw a house") instead of following it strictly, my results suggest, once more, that participants in this group are active and vigorous. Furthermore, this group showed fewer drawings with a [window on the roof] compared with the other groups; considering that a [window on the roof] is meant to allow for house dwellers to see the outside while not being able to be seen from the outside, it denotes an inclination toward protecting one's privacy (Leibowitz, 1999). Again, the lower frequency of this indicator denotes that participants 


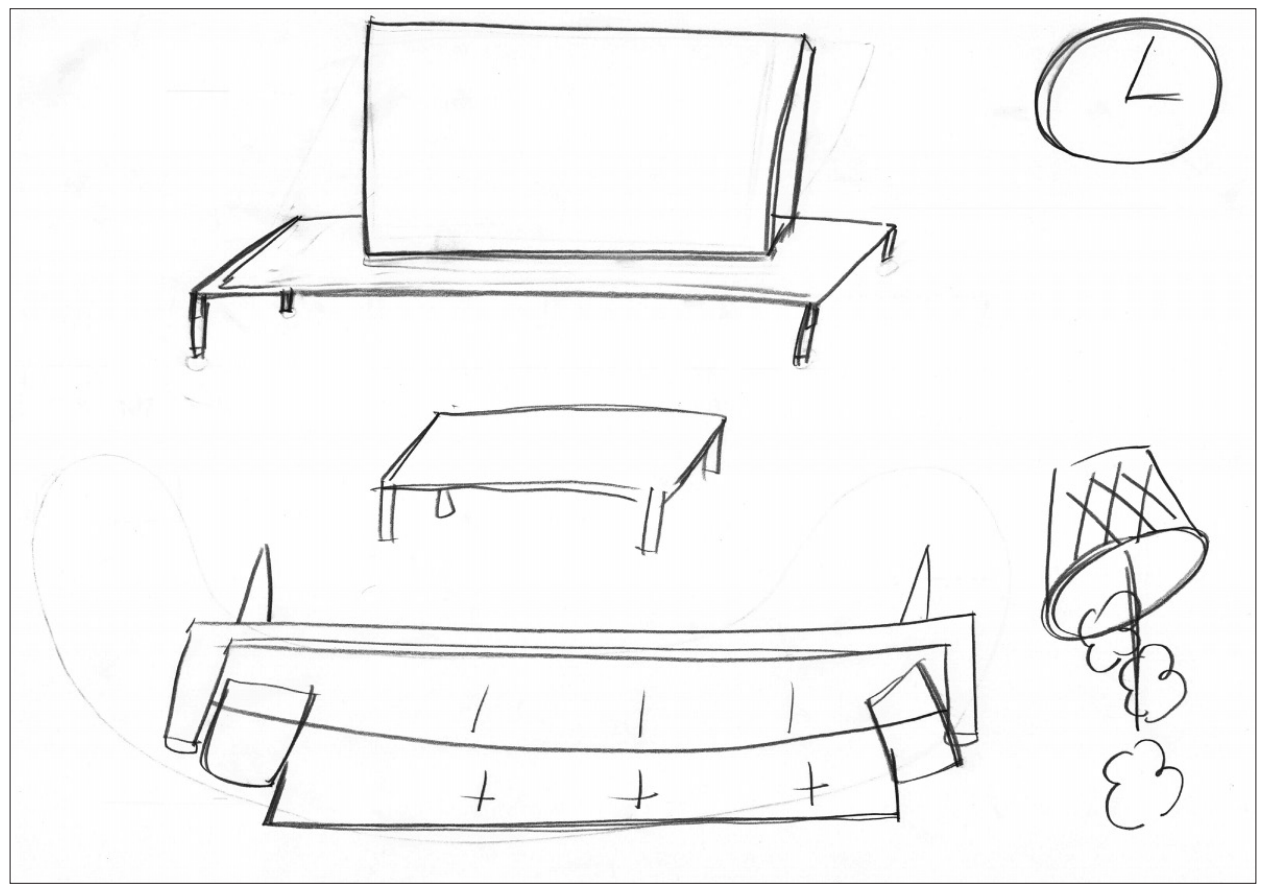

Fig. 5. Example of [No Boundary Line] and [Mix of Perspectives] in the Room-Drawing-Test by a Participant in the Alexithymic Group

in this group have high confidence.

From the above, this group seems to be vigorous and confident, but concomitantly, their drawings (e.g., Fig. 7) may create a childlike impression and may lack subtlety. Thus, although this group was named "Emotionally Stable," it may be that such emotional stability does not come from maturity, but from their childlike simplicity. The higher frequency of drawings with one or more [plant] may also denote childishness; when adults draw flowers in their House-Drawings - which are often seen in children's House-Drawings - it signifies that they are regressing to earlier developmental stages and acting in a childish, immature, or age-inappropriate manner, or that they have selfappreciation tendencies (Takahashi, 2011).

Although this group showed several significant results for the House-Drawing-Test, it showed only one for the Room-Drawing-Test; it showed more drawings with a [calendar] compared with the other groups. This could be interpreted in various ways: it might indicate a preference for punctuality; a tendency to plan ahead; an inclination to focus on external standards; etc. However, these are only speculations and require further investigation for confirmation.

\section{Key Points of the Study}

To assess participants' alexithymia tendencies correctly, I followed prior recommendations that emphasized the TAS-20 total score as a non-accurate parameter for assessing 


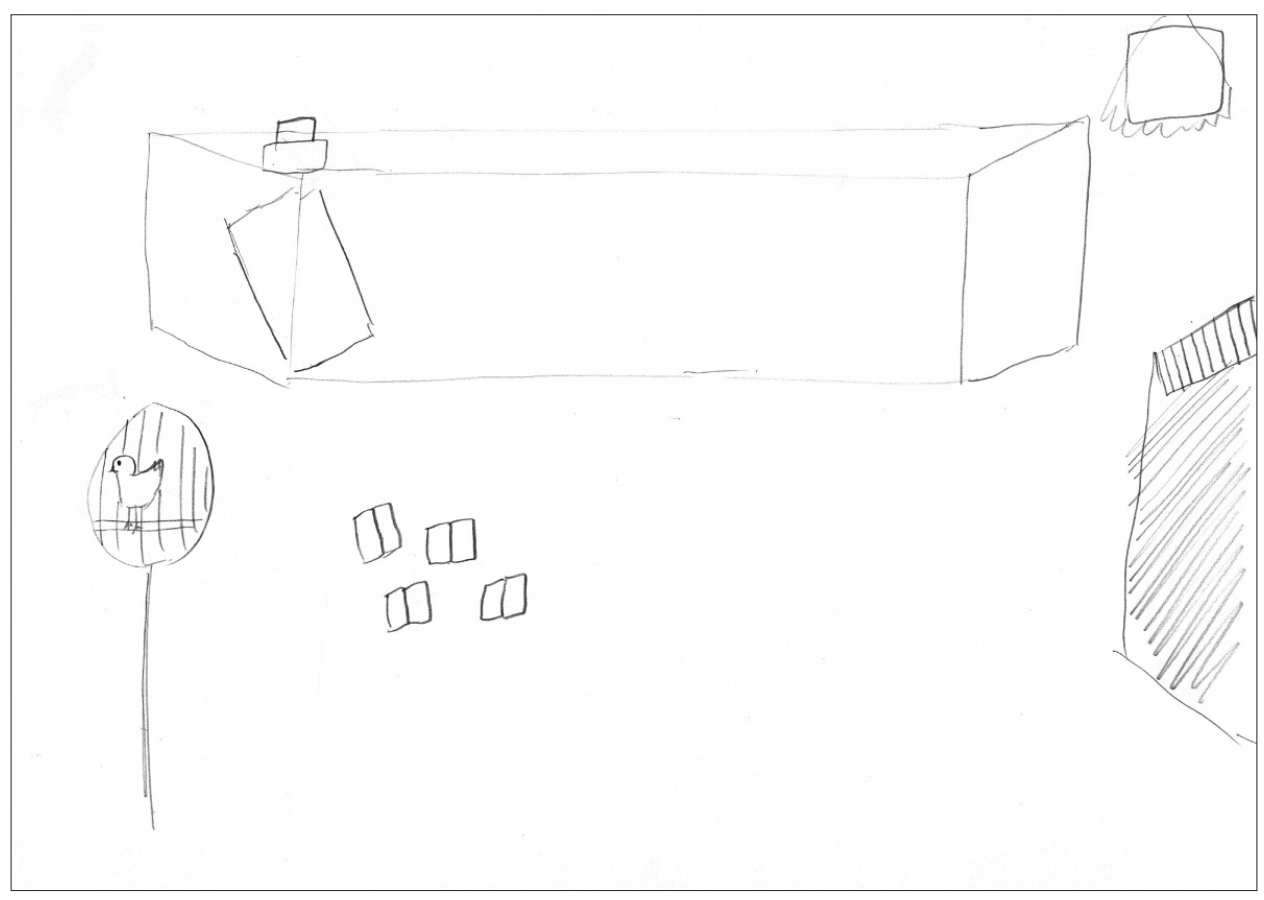

Fig. 6. Another Example of [No Boundary Line] and [Mix of Perspectives] in the Room-Drawing-Test by a Participant in the Alexithymic Group

alexithymia. Instead, I classified participants into four subgroups through cluster analysis and examined the characteristics of their drawings. Specifically, both the Neurotic and Alexithymic groups showed higher TAS-20 total scores compared with the other two groups. If I was to choose the TAS-20 total score as an accurate parameter for alexithymia, the Neurotic group would have been the most alexithymic of the four subgroups; nonetheless, I focused on the EOT subscale as the accurate parameter, so the group with the highest EOT (i.e., the Alexithymic group) was deemed as truly the most alexithymic.

Participants included in the Neurotic group were considered to often/easily experience emotional confusion and to have difficulty in communicating their feelings to others. Based on their drawings, participants in this group were characterized by closedness toward the external world/others. Meanwhile, they differentiated between the internal and external worlds sharply and were more conscious toward, and had a greater subjective relationship with, their internal worlds.

Although the Alexithymic group showed no significant characteristics in its HouseDrawings compared with the other groups, this group showed characteristic features regarding its Room-Drawings, especially regarding perspective and space composition. In this group, it was suggested that the distinction between the internal and external worlds was often vague and that there was lack of an integrated viewpoint; accordingly, the interior space tended to be flat and not sufficiently arranged as a living space. 


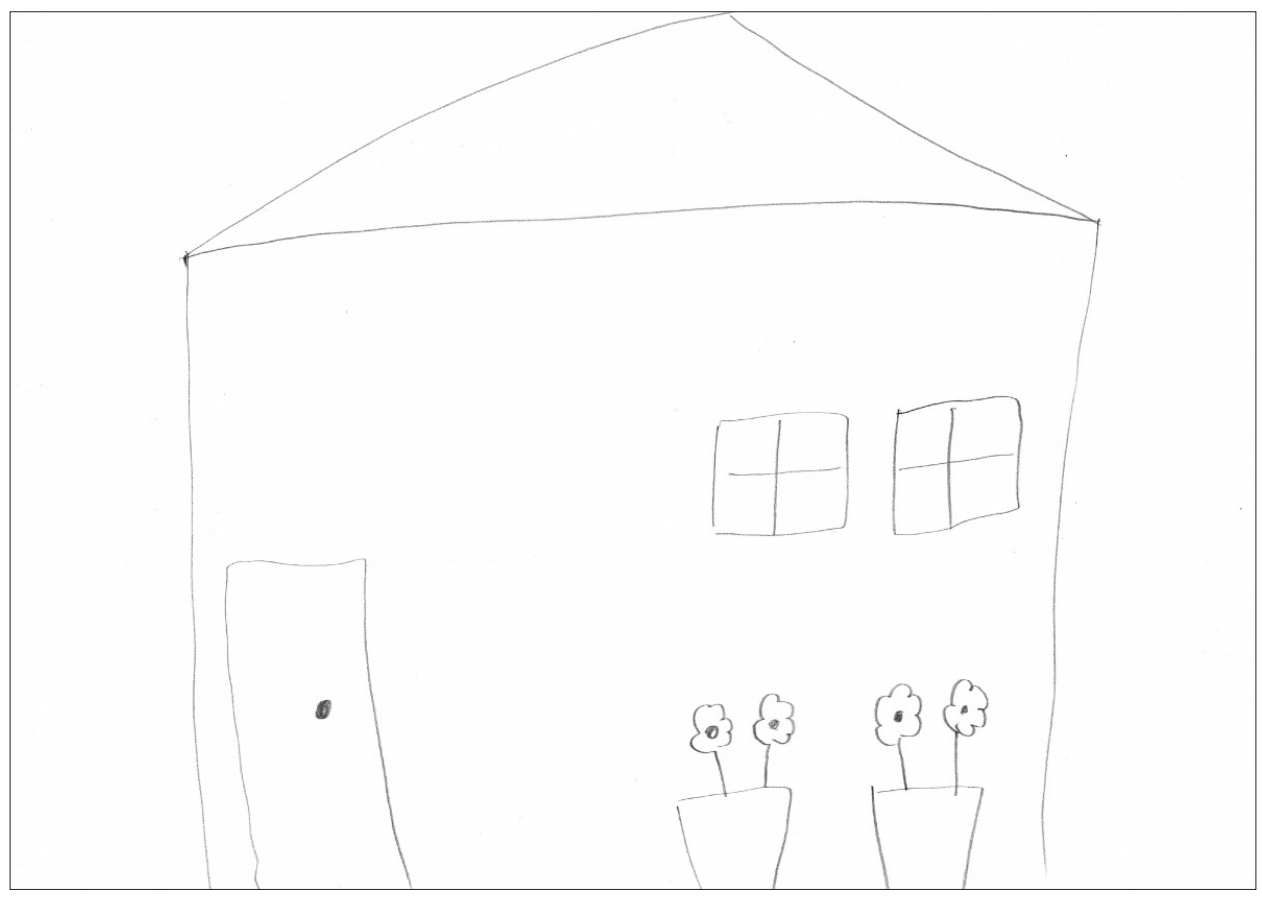

Fig. 7. Example of [Large House] and [Plant] in the House-Drawing-Test by a Participant in the Emotionally Stable Group

Thence, participants in this group were considered to have little concern about their own internal world or to face difficulties to involve with it.

Although the difference between the Neurotic and Alexithymic groups was not clearly depicted by the simple use of the TAS-20 total score or by the House-DrawingTest, it was highlighted by the Room-Drawing-Test. This suggests that the latter can provide valuable information regarding individuals' attitudes toward their internal and external worlds for assessing alexithymia tendency. Therefore, the usefulness of this method for understanding the features of psychosomatic conditions in a broad sense has been demonstrated in the above-mentioned studies.

Further, although the Room-Drawing-Test can be analyzed from various viewpoints, this study confirms the importance of paying attention to perspective (i.e., the following characteristics: [first-person view], [lack of depth], [mix of perspectives]) and to the degree of differentiation/elaboration of the interior space (i.e., [no boundary line], [decoration], [food and drinks]) when analyzing Room-Drawings.

\section{Study Limitations}

First, the TAS-20 showed internal consistency problems; specifically, the alpha coefficient of the EOT subscale was not sufficient. Despite the reoccurrences of this problem in the literature, this denotes that the EOT subscale may not assess a single concept, but different psychological traits. Therefore, interpretations about the results of 
this subscale should be made with caution, and further verification of the findings of this study using methods other than the TAS-20 to assess alexithymia is required.

Second, my results were based on data collected from female undergraduate students in a single Japanese university; thus, generalizations should be made with caution. Since women tend to draw entrance ways, chimneys, curtains, and additional objects more often than men in the House-Drawing-Test (Takahashi, 1974), such gender differences may also occur in the Room-Drawing-Test. Additionally, owing to teenagers experiencing increased self-consciousness - that may become excessive- their DIF and DDF scores are reportedly higher compared with other age groups (Moriguchi et al., 2007). Thence, given that most of the participants were under 20 years old, those included in the Internally Oriented and Neurotic groups may be more representative of most teenagers/be more common, whereas those in the Emotionally Stable group may be less representative/ common. Thus, further research with a larger sample, conducted in wider areas, with a wider range of age groups, and in both sexes are warranted.

Third, content analysis of Room-Drawings did not show significant betweensubgroup differences; this may have occurred because the analysis indicators focused solely on whether the object was drawn or not. Thus, further research should be conducted with more detailed/elaborated drawing content analysis methods. I also suggest further research to clarify what each drawing feature means in the RoomDrawing-Test.

\section{CONFLICT OF INTEREST}

There are no conflicts of interest to be declared.

\section{REFERENCES}

Arimura, T., Komaki, G., Murakami, S., Tamagawa, K., Nishikata, H., Kawai, K., Nozaki, T., Takii, M., \& Kubo, C. (2002). Development of the Structured Interview by the modified edition of Beth Israel Hospital Psychosomatic Questionnaire (SIBIQ) in Japanese edition to evaluate alexithymia. Japanese Journal of Psychosomatic Medicine, 42(4), 259-269. https://doi.org/10.15064/jjpm.42.4_259

Bagby, R. M., Parker, J. D. A., \& Taylor, G. J. (1994). The twenty-item Toronto Alexithymia Scale: I. Item selection and cross-validation of the factor structure. Journal of Psychosomatic Research, 38(1), 23-32. https://doi.org/10.1016/0022-3999(94)90005-1

Bagby, R. M., Parker, J. D. A., \& Tailor, G. J. (2020). Twenty-five years with the 20-item Toronto Alexithymia Scale. Journal of Psychosomatic Research, 131, Article 109937. https://doi.org/ 10.1016/j.jpsychores.2020.109940

Bagby, R. M., Tailor, G. J., \& Parker, J. D. (1994). The twenty-item Toronto Alexithymia Scale: II. Convergent, discriminant, and concurrent validity. Journal of Psychosomatic Research, 38(1), 33-40. https://doi.org/10.1016/0022-3999(94)90006-X

Briggs, S. R., \& Cheek, J. M. (1986). The role of factor analysis in the development and evaluation of personality scales. Journal of Personality, 54(1), 106-148. https://doi.org/10.1111/j.1467-6494. 1986.tb00391.x

Buck, J. N. (1948). The H-T-P technique: A qualitative and quantitative scoring manual. Journal of 
Clinical Psychology, 4(4), 317-396. https://doi.org/10.1002/1097-4679(194810)4:4<317::AIDJCLP2270040402>3.0.CO;2-6

Furuno, Y. (2005). A study on the coping style and the psychological posture of hyperventilation syndrome patients. Journal of Japanese Clinical Psychology, 23(1), 64-74.

Inoue, R. (1984). Fukei-kosei-ho to kaoku-ga-ni-men-ho: Seishin-bunretsu-byo-sha no "sumai"-kata kara mita "fukei" shiron [Landscape Montage Technique and Double-sided House-Drawing Technique: An essay on "landscape" from the viewpoint of "living" style of schizophrenic patient]. In Y. Yamanaka (Ed.), Nakai Hisao chosaku-shu bekkan 1. Fukei-kosei-ho (pp. 163-187). Iwasaki Academic Publisher.

Kandri, T. A., Bonotis, K. S., Floros, G. D., \& Zafiropoulou, M. M. (2014). Alexithymia components in excessive internet users: A multi-factorial analysis. Psychiatry Research, 220(1-2), 348-355. https://doi.org/10.1016/j.psychres.2014.07.066

Komaki, G., Maeda, M., Arimura, T., Nakata, A., Shinoda, H., Ogata, I., Shimura, M., Kawamura, N., \& Kubo, C. (2003). The reliability and factorial validity of the Japanese version of the 20-item Toronto Alexithymia Scale (TAS-20). Japanese Journal of Psychosomatic Medicine, 43(12), 839-846. https://doi.org/10.15064/jjpm.43.12_839

Leibowitz, M. (1999). Interpreting projective drawings: A self psychological approach. Brunner/Mazel.

Li, S., Zhang, B., Guo, Y., \& Zhang, J. (2015). The association between alexithymia as assessed by the 20item Toronto Alexithymia Scale and depression: A meta-analysis. Psychiatry Research, 227(1), 1-9. https://doi.org/10.1016/j.psychres.2015.02.006

Moriguchi, Y., Maeda, M., Igarashi, T., Ishikawa, T., Shoji, M., Kubo, C., \& Komaki, G. (2007). Age and gender effect on alexithymia in large, Japanese community and clinical samples: A cross-validation study of the Toronto Alexithymia Scale (TAS-20). BioPsychoSocial Medicine, 1, Article 7. https://doi.org/10.1186/1751-0759-1-7

Nishi, T. (2018). Overview and prospects of studies on Room-Drawing-Test: Considering image of a house. Kyoto University Research Studies in Education, 64, 207-219. http://hdl.handle.net/2433/231347

Samizo, T. (2006). A study of the boundary drawn in the Room-Drawing-Test from perspective: From the relation to YG personality inventory. Japanese Bulletin of Arts Therapy, 37(1-2), 57-66.

Sifneos, P. E. (1973). The prevalence of 'alexithymic' characteristics in psychosomatic patients. Psychotherapy and Psychosomatics, 22(2-6), 255-262. https://doi.org/10.1159/000286529

Sriram, T. G., Pratap, L., \& Shanmugham, V. (1988). Towards enhancing the utility of Beth Israel Hospital Psychosomatic Questionnaire. Psychotherapeutic Psychosomatics, 49(3-4), 205-211. https://doi.org/ $10.1159 / 000288085$

Takahashi, M. (1974). Byoga tesuto nyumon: HTP Tesuto [Introduction to drawing test: HTP Test]. Bunkyoshoin.

Takahashi, Y. (2011). Byoga tesuto [Drawing test]. Kitaohji Shobo.

Taylor, G. J., \& Bagby, R. M. (2004). New trends in alexithymia research. Psychotherapy and Psychosomatics, 73(2), 68-77. https://doi.org/10.1159/000075537

Taylor, G. J., Bagby, R. M., \& Parker, J. D. A. (1997). Disorders of affect regulation: Alexithymia in medical and psychiatric illness. Cambridge University Press. https://oi.org/10.1017/ CBO9780511526831

Taylor, G. J., Bagby, R. M., \& Parker, J. D. A. (2003). The 20-item Toronto Alexithymia Scale: IV. Reliability and factorial validity in different languages and cultures. Journal of Psychosomatic Research, 55(3), 277-283. https://doi.org/10.1016/S0022-3999(02)00601-3

Thorberg, F. A., Young, R. M., Sullivan, K. A., \& Lyvers, M. (2009). Alexithymia and alcohol use disorders: A critical review. Addictive Behaviors, 34(3), 237-245. https://doi.org/10.1016/j.addbeh. 2008.10.016

Tokuda, K. (1981). Anorexia Nervosa ni kansuru ichi kenkyu: Byoga tesuto wo mochiite [A study on Anorexia Nervosa: Using drawing test] [Unpublished master's thesis]. Kyoto University, Japan.

Ueno, M., Maeda, M., \& Komaki, G. (2014). Different subgroups of high-scores on the TAS-20 based on the big five personality traits. Personality and Individual Differences, 68, 71-76. https://doi.org/ 10.1016/j.paid.2014.04.012

Umemura, K. (2015, October 11). Seinen-ki joshi ni okeru shinshin-sho to kaoku-ga shitsunai-ga tono kanren: Nai-teki sekai oyobi gai-teki kankyo tono kakawari-kata ni chumoku-site [The relationship of 
psychosomatic diseases to House-Drawing-Test and Room-Drawing-Test in adolescence: Focusing on the interactions with internal world and external surroundings] [Paper presentation]. The 29th conference of the Japan Association of Sandplay Therapy, Miyagi, Japan.

Umemura, K. (2016, October 16). Kaoku-ga shitsunai-ga kara mita seinen-ki joshi shinshin-sho kanja no shinri-teki tokucho: Arekishisaimia tono kanren kara [The psychological features of adolescent psychosomatic patients reflected in House-Drawing-Test and Room-Drawing-Test: In relation to alexithymia] [Paper presentation]. The 30th conference of the Japan Association of Sandplay Therapy, Osaka, Japan.

Westwood, H., Kerr-Gaffney, J., Stahl, D., \& Tchanturia, K. (2017). Alexithymia in eating disorders: Systematic review and meta-analyses of studies using the Toronto Alexithymia Scale. Journal of Psychosomatic Research, 99, 66-81. https://doi.org/10.1016/j.jpsychores.2017.06.007

Yamamori, M. (1999). Shitsunai-ga ni hyogen-sareru nai-teki sekai nitsuite no ichi kosatsu: Kyokaidukerareteinai kukan-imeji wo megutte [A study of the "Raum Test": On the "Raum" image with no boundary]. Kyoto University Research Studies in Education, 45, 373-381. http://hdl.handle.net/ $2433 / 57320$

Yamamori, M. (2002). Features of spatial composition and its meanings in patients with Grave's Disease: Subjectivity derived from analysis of the "Room-Drawing Test". Journal of Japanese Clinical Psychology, 20(1), 35-43.

(Manuscript received 1 September, 2020; Revision accepted 11 November, 2020; Released online in J-STAGE as advance publication 19 February, 2021) 